\title{
Acid Phosphatases from Different Organs and Animal Forms Compared by Starch-gel Electrophoresis
}

\author{
L. - G. LU N D I N* a n d A. C. A L L I S O N \\ National Institute for Medical Research, Mill Hill, London, England
}

\begin{abstract}
Acid phosphatases from several human, rat, mouse, hamster, rabbit, chicken, and axolotl tissues have been compared by electrophoresis on starch and polyacrylamide gels. Multiple components with this activity were demonstrated especially in the livers, spleens, and kidneys.

In livers from all the mammals investigated a zone containing between 10 and 17 bands appeared, moving towards the anode at $\mathrm{pH}$ 6.0. In the mouse, rat, and hamster some of the acid phosphatases moved in the opposite direction at this pH. The axolotl showed a less complicated pattern.

Density gradient centrifugation seemed to indicate that the multiple components in rat liver and kidney were proteins of equal size.

Some ontogenetic differences were found, notably in liver. Results with different inhibitors, activators, and substrates used in combination with the electrophoresis emphasized the multiplicity of the enzymes present.

In human liver $\beta$-glucuronidase was found to exist in three different forms.

Reasons were given for concluding that the patterns obtained were not artefacts of the technique used. Thus acid phosphatases represent a complex group of enzymes in different tissues and animal forms. Whether these enzymes are always lysosomal is not yet firmly established.
\end{abstract}

A cid phosphatases represent a group of hydrolases present in the lysosomes
of a variety of animal cell types. This was first shown by de Duve and his
colleagues ${ }^{1}$ for liver cells and later on for kidney cells. ${ }^{2}$ The lysosomal concept,
which was originally a biochemical one, has been correlated with cytochemical
findings mostly made with the Gomori technique for acid phosphatases. After
staining with this method, dense rounded granules which are believed to be
the lysosomes can be seen by light microscopy ${ }^{3}$ and in electron micrographs. ${ }^{4,5}$
When the acid phosphatase activity is measured in homogenates from
different animal tissues with different substrates, inhibitors, and hydrogen

* Permanent address: Institute for Medical Genetics, Uppsala, Sweden. 
ion concentrations, it is clear that more than one enzyme is present, e.g. in liver and spleen from different species. ${ }^{6-11}$ The question whether all these enzymes are present in lysosomes has not been satisfactorily resolved. Neil and Horner ${ }^{11}$ concluded that they could relate one of the acid phosphatases in mouse liver to the lysosomal fraction whereas three other enzymes with this activity were present mostly in other fractions. One of these seems to be the microsomal glucose-6-phosphatase.

By cytochemical methods some authors have found acid phosphatases in both lysosomes and the Golgi apparatus, ${ }^{12-14}$ but others have only found it in the lysosomes..$^{5,15}$ Sometimes diffuse cytoplasmic staining is seen but its nature is uncertain. 4,16

Allen et al. ${ }^{17}$ have described genetic variations in the acid phosphatases from Tetrahymena. These enzymes were separated by starch gel electrophoresis. Relatively little work has been done on electrophoretic separation of acid phosphatases in higher animals. ${ }^{18-25}$ Barka ${ }^{19,26}$ found six bands of acid phosphatase activity in rat liver after a combined separation by chromatography and electrophoresis on polyacrylamide gel.

Sur et al. ${ }^{24,25}$ working with human prostate material, gave a brief report that they had found at least thirteen components after electrophoresis on starch gel. Reith et $a l .^{27}$ using column chromatography, obtained four peaks of acid phosphatase activity from both human and rat livers.

The present investigation shows a similar picture of human material to that described by Sur et al., and a more complex one for animal material than earlier reports.

\section{MATERIAL AND METHODS}

Preparation of tissues. The animals were killed by cervical dislocation or with ether and the required tissues were removed, homogenized in distilled water, frozen and thawed four times. The amounts of tissue and water were roughly $1: 2$. The homogenates were centrifuged at $100000 \mathrm{~g}$ for $1 / 2 \mathrm{~h}$ and the supernatant was removed and kept frozen at $-10^{\circ} \mathrm{C}$ until used.

The human samples included autopsy material and blood from healthy individuals. The white blood cells were separated from whole blood by letting the blood stand for some hours and then lightly centrifuging the cells. The erythrocytes go first to the bottom and the leucocytes are layered on top of them. It is then possible to remove carefully enough of the white cells to make a small homogenate by freezing and thawing.

Electrophoresis. For starch-gel electrophoresis Connaught starch and either a discontinuous buffer system according to Hopkinson et al. ${ }^{22}$ or a continuous system with acetate buffer has been used. The first system contained as a gel buffer $0.0025 \mathrm{M}$ succinic acid and $0.0046 \mathrm{M}$ tris which gives $\mathrm{pH}$ 6.0. As bridge buffer, $0.41 \mathrm{M}$ citrate to $\mathrm{pH} 6.0$ with $\mathrm{NaOH}$ was initially used, but later the concentration of citrate was reduced to $0.1 \mathrm{M}$ to decrease the chelating effect of this compound. The acetate buffer was made from stock solutions of acetic acid and sodium acetate which were 1.5 M. They were mixed to give pH 5.3 or 4.8 and $225 \mathrm{ml}$ of this was diluted to 31 with water giving a final molarity of 0.113 . This was used as bridge buffer and the gel buffer was diluted with water (1:5).

The apparatus used for the starch-gel electrophoresis was a level metal plate on which were placed glass plates and frames of plastic $(6 \mathrm{~cm} \times 27 \mathrm{~cm})$. The starch solution was poured on to a glass plate and kept there by the frame. The vessels for the bridge buffer and the electrodes were made of plastic and contained two compartments, one for the electrode and the other for connection by pieces of lint with the gel. The two compartments were connected by lint. Small amounts of the homogenate supernatants in pieces of filter paper (Whatman 3MM) were inserted into a slit in the middle of the gel. At $200 \mathrm{~V}$ 
Fig. 1. Schematic drawing of the apparatus used for polyacrylamide electrophoresis.

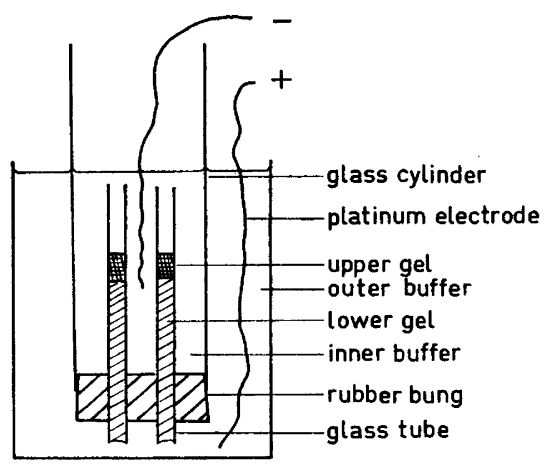

over the whole system the discontinuous buffers gave a starting current around $10 \mathrm{~mA}$ which after $4 \mathrm{~h}$ had increased to $20 \mathrm{~mA}$. The corresponding figures for the acetate buffer were 20 and $30 \mathrm{~mA}$.

For polyacrylamide gel electrophoresis glass tubes with an inner diameter of $5 \mathrm{~mm}$ were used. Two tubes were fitted into a rubber stopper and this was inserted into a large glass tube which served as compartment for one of the electrodes. The large tube was vertically immersed in a beaker containing buffer, which served as the other electrode vessel (Fig. 1).

Polyacrylamide gels were made with final concentrations of 7.5 and $\mathbf{2 . 5} \%$ acrylamide $(w / v)$ and 0.2 and $0.63 \%$ bisacrylamide for the lower gel and the protein concentrating upper gel, respectively. Tetramethylethylene diamine (TEMED) for setting the gels was titrated with acetic acid to the required $\mathrm{pH}, 5.8$ for lower gel and 4.1 for upper gel. Ammonium persulfate of final concentration $0.07 \%$ is added to set the gels. Acetate buffer $0.1 \mathrm{M}$, pH 5.4, containing $1 \% \beta$-alanine was used in the vessels.

Specific staining. The gels were stained for acid phosphatases with either $\alpha$-naphthylphosphate $(\alpha-N P)$, Fast Garnet GBC salt as an azocoupler (100 mg of each/100 ml acetate buffer $\mathrm{pH}$ 5.0) and $2 \mathrm{~g}$ sodium chloride, or with the lead precipitating technique with $\beta$ glycerophosphate ( $\beta$-GP) as substrate (Gomori). The gels were incubated overnight at room temperature in a solution of $0.01 \mathrm{M} \beta$-glycerophosphate, $0.004 \mathrm{M}$ lead nitrate and $0.1 \mathrm{M} \mathrm{MgCl}$ in $100 \mathrm{ml}$ of $0.05 \mathrm{M}$ acetate buffer pH 5.0. After washing the gel in $1 \%$ acetic acid a $1 \%$ solution of ammonium sulphide was added.

Staining for $\boldsymbol{\beta}$-glucuronidase was performed by placing a filter paper on the sliced gel and pouring on a solution of $5 \mathrm{mg} 8$-hydroxyquinoline glucuronide and $7 \mathrm{mg}$ Blue RR salt in $10 \mathrm{ml}$ acetate buffer, $0.1 \mathrm{M}, \mathrm{pH} \mathbf{5 . 3}$.

Density gradient centrifugations. $1.5 \mathrm{ml}$ of 10,20 and $30 \%$ sucrose solutions were layered upon each other. The gradients were allowed to stand for at least $6 \mathrm{~h}$ to make them more continuous; $0.5 \mathrm{ml}$ of the sample was introduced on top of the gradient just before the centrifugation was started. To the sample were added two marker-proteins, albumin labelled with ${ }^{125} \mathrm{I}$ and $\gamma$-globulin labelled with ${ }^{181} \mathrm{I}^{28}$ The centrifuge was an MSE ultracentrifuge with a $3 \times 5 \mathrm{ml}$ swing-out rotor. It was refrigerated at $4^{\circ}$ during the runs which lasted for $16-17 \mathrm{~h}$ at a speed of $40000 \mathrm{rpm}$. Fractions of equal size were collected from the bottom of the tubes. The radioactivity in each fraction was measured in two energy regions to give ${ }^{125}$ I and ${ }^{131} \mathrm{I}$ separately. The acid phosphatase activity was determined with $p$-nitrophenyl phosphate as substrate.

\section{RESULTS}

Starch gel. The different patterns found can be seen in the photographs (Figs. 2-6) and diagrams (Figs. 7-14). With the discontinuous buffer system, $200 \mathrm{~V}$ over the whole, and a running time of $2 \mathrm{~h}$, a rather blurred picture

Acta Chem. Scand. 20 (1966) No. 9 
developed from some tissues on the anodal side of the insertion slit. However, when the time was increased to $4 \mathrm{~h}$, part of the reason for the blurring became evident. For instance, in human tissues the broad zone of activity divided into 13-17 separate bands (Figs. 2, 3, and 7). Similar results were obtained with livers from mice, rats (Fig. 9), rabbits (Fig. 11), and hamsters (Fig. 10). Unfortunately it has not been possible so far to obtain from the livers of these animals patterns as well resolved as those from human tissues. Mouse and rat kidneys

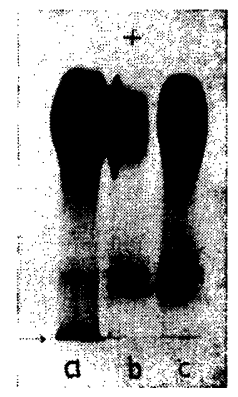

Fig. 2. Photograph of starch gel with human (a) prostate, (b) liver, and (c) kidney. Buffer system: Succinic acid-Tris-citric

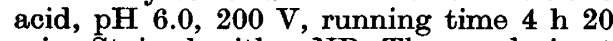
min. Stained with $\alpha$-NP. The anode is at the top of the picture.

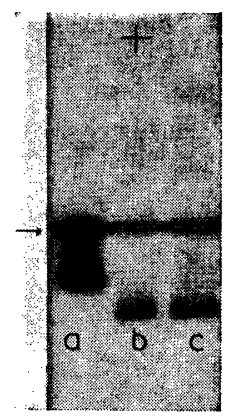

Fig. 4. Photograph of starch gel with kidneys from (a) rat, (b) mouse, and (c) hamster. Same system as Fig. 2, running time 3 h. $\alpha \cdot N P$.

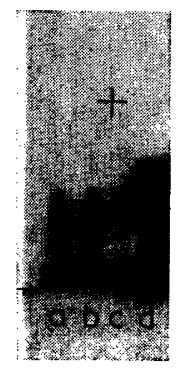

Fig. 3. Photograph of starch gel with human, $(a-c)$ leucocytes from three different individuals, and (d) liver. Same system as Fig. 2, running time 3 h. $\alpha$-NP.

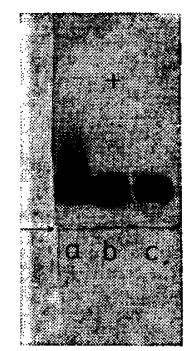

Fig. 5. Photograph of starch gel with newly hatched chicken (1 day) (a) liver, (b) kidney, and (c) brain. Same system as Fig. 2 , running time $3 h$. $\alpha$-NP.

give three and five bands, respectively, moving towards the cathode. The human and the rabbit do not have any acid phosphatases on that side when the electrophoresis is carried out at $\mathrm{pH} 6.0$, though in the acetate system where the $\mathrm{pH}$ is 5.3 we find some of the components from human (Fig. 8) and rabbit tissues on the cathodal side of the origin. The resolution is, however, much less satisfactory in the simple continuous buffer system, no distinct separate bands being visible in most cases but the staining with $\beta$-glycero- 


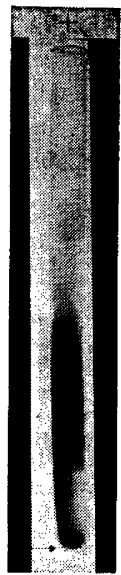

Fig. 6. Photograph of polyacrylamide gel with human spleen. Running time $4 \mathrm{~h}$, $160 \mathrm{~V} . \alpha-\mathrm{NP}$.

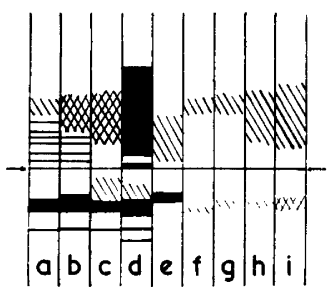

Fig. 8. Diagram of starch gel with human (a) liver, (b) kidney, (c) spleen, (d) prostate, (e) leucocytes, (f) liver (g) kidney, (h) spleen and (i) prostate. Acetate buffer pH $5.3,200 \mathrm{~V}$, running time $4 \mathrm{~h} .(\mathrm{a}-\mathrm{e}) \alpha-\mathrm{NP}$, (f-i) $\beta$-GP.

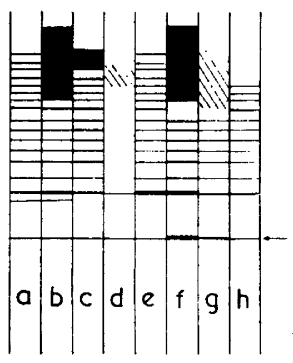

Fig. 7. Diagram of starch gel with human (a) liver, (b) kidney, (c and d) spleen, (e) pancreas, (f-g) prostate, (h) leucocytes. Buffer system: Succinic acid-Tris-citric acid, pH 6.0, $200 \mathrm{~V}$, running time $4 \mathrm{~h}$. d and g $\beta$-GP as substrate, the others $\alpha$-NP.
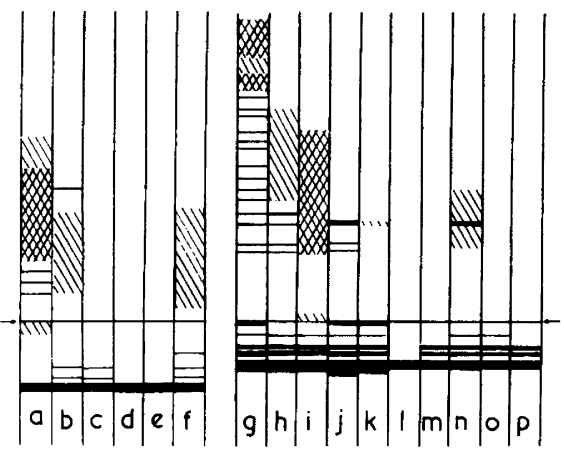

Fig. 9. Diagram of starch gel with mouse (a) adult liver, (b) foetal liver, (c) ad. kidney, (d) foet. kidney, (e) ad. brain, (f) ad. spleen, and rot $(\mathrm{g})$ ad. liver, (h) newborn liver, (i) ad. spleen, (j) ad. kidney (k) newb. kidney, (l) ad. brain, (m) newb. brain, (n) ad. testis, (o) ad. prostate, (p) ad. kidney $\beta$-GP. $(a-o) \alpha$-NP. Same conditions as Fig. 7.

phosphate was always much stronger when this buffer was used as compared to the succinic acid-tris-citric acid system. The lower activity in the last buffer is probably due to the chelating effect of citrate. Golberg et al. ${ }^{29}$ found citrate to be strongly inhibitory for $\beta$-glycerophosphatase. We could partly overcome this by adding $\mathrm{Mg}^{2+}$-ions to the staining solution.

Acta Chem. Scand. 20 (1966) No. 9 


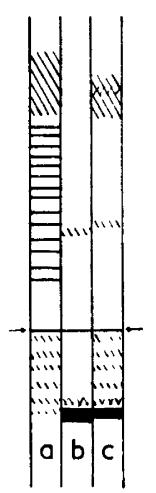

Fig. 10. Diagram of starch gel with hamster (a) liver, (b) kidney, (c) spleen. Same conditions as Fig. 7.

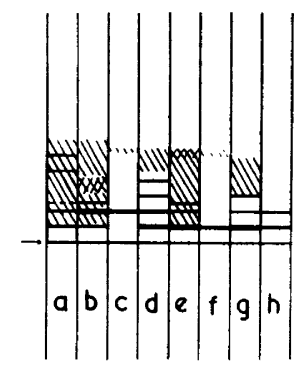

Fig. 11. Diagram of starch gel with rabbit (a) adult liver, (b and c) newborn liver, (d) ad. kidney, (e) and (f) newb. kidney, (g) ad. spleen, (h) newb. spleen. (c and f) $\beta$-GP, all others $\alpha-N P$. Same conditions as Fig. 7 .

Human prostate has a strong band that moves very little at $\mathrm{pH}$ 6.0. This component was not seen in any of the other human tissues investigated (Fig. 7). The patterns of the human tissues seem to be more alike when compared with each other than are those of the mouse and rat tissues. If we compare the pictures from liver and kidney from these three species (Figs. 7 and 9) we can see that human kidney acid phosphatases resemble those from liver, but that mouse and rat kidney have different anodal patterns than those obtained with the livers from these animals.

When the activities against the two substrates, $\alpha$-naphthylphosphate and $\beta$-glycerophosphate, were compared with the discontinuous buffer system human prostate (Fig. 7) showed a similar pattern in both cases. Only samples with high activities gave staining with $\beta$-glycerophosphate. Some of the rat tissues gave the ordinary cathodal pattern with this substrate (Fig. 9). The weaker anodal components, though giving rather strong staining with $\alpha$ naphthylphosphate, were not visible when the lead precipitation technique was used. When acetate buffer was used during the electrophoresis the patterns obtained with the two substrates seemed to be comparable for human tissues (Fig. 8) and axolotl liver (Fig. 13). The intensity and thickness of the chicken and rat kidney bands are not so pronounced with the Gomori technique as with the azo dye method. This may be due to differential activity of the components within a zone but can more probably be explained by lower sensitivity of the lead precipitation method. The foetal chicken kidney may also show a component which is active with $\beta$-GP but not with $\alpha-\mathrm{NP}$.

Some incubations were made with $p$-nitrophenylphosphate as a chromogenic substrate after electrophoresis with the acetate buffer $\mathrm{pH}$ 4.8. The product, $p$-nitrophenol, is easily diffusible and because of that it does not give any sharp bands. We did, however, obtain a rough indication of the location of the regions with strong enzyme activity. The strongest stain was 


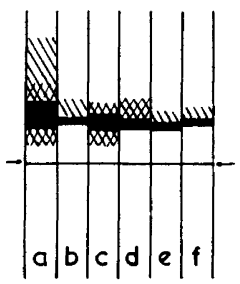

Fig. 12. Diagram of starch gel with chicken (a) adult liver, (b) newly hatched liver, (c) ad. kidney, (d) new. hat. kidney, (e) ad. lung, (f) new hat. lung. Same conditions as in Fig. 7, running time 5 h. $\alpha-N P$.

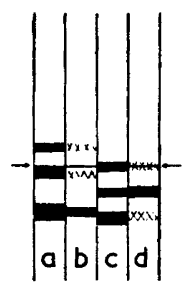

Fig. 13. Diagram of starch gel with young axolotl-larvae, (a, c and d) liver, (b) kidney. (a and b) Succinic acid-Tris-citric acid buffer, $\mathrm{pH}$ 6.0. (c and d) Acetate buffer pH 4.8. (a, b and c) $\alpha-N P$, (d) $\beta$-GP. $200 \mathrm{~V}$, $2 \mathrm{~h}$ running time.

in the same place as one would expect from results with $\alpha$-NP for all the samples run, which included mouse spleen, liver and kidney, rat kidney, and chicken and rat spleen.

$\beta$-Glucuronidase. Investigation of another group of lysosomal enzymes, $\beta$-glucuronidases, by starch gel electrophoresis and the staining method described, revealed several different distinct bands of activity, possibly representing different enzymes with $\beta$-glucuronidase activity. Human liver had three components, human kidney two, with the same mobilities as two of the liver enzymes (Fig. 14). Human leucocytes had only one band but this was quite different from any of the three liver bands.

The staining reaction was rather weak for these enzymes and difficult to reproduce probably because of the presence of citrate in the gel. Mills et al. ${ }^{30}$ reported that $\beta$-glucuronidases from ox spleen were inhibited by acids with more than one carboxyl group and especially by those containing a hydroxyl group. Citric acid thus strongly inhibited two of the $\beta$-glucuronidase fractions. It is unlikely that this inhibition can be overcome by addition of metal ions because the citrate probably forms a complex with the active center of the enzyme.

Polyacrylamide gel. In order to see whether the pattern from human tissues would remain comparable in a different electrophoretic system we used polyacrylamide as a supporting medium. The results with this system gave a very similar picture to that shown by starch-gel electrophoresis (Fig. 6). It was necessary to have an amino acid in the vessel buffer, and $\beta$-alanine seemed to

Fig. 14. Diagram of starch gel stained for $\beta$-glucuronidase (8-hydroxyquinoline glucuronide) with human (a) leucocytes, (b) kidney, and (c) liver. Same system as in Fig. 7.

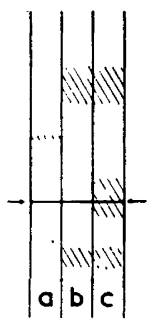

Acta Chem. Scand. 20 (1966) No. 9 
give better resolution than glycine. If only TEMED and acetic acid were used the resolution was much less satisfactory and no individual bands were visible. Work is in progress to separate these acid phosphatases on a preparative scale. With the low $\mathrm{pH}$ used for the electrophoresis some of the acid phosphatases from animal tissues will move in the cathodal direction and never reach the gel, as does hemoglobin. To study these enzymes it will be necessary to use an upper concentrating gel with a $\mathrm{pH}$ around 7.0 or higher and to reverse the electrodes. Unfortunately one cannot get all the acid phosphatases from, e.g., rat liver into one gel with the low $\mathrm{pH}$ we have used which gives good resolution of those components that do penetrate the gel.

Inhibition and activation. Fluoride ions are reported to inhibit acid phosphatases both with bio- and cytochemical methods ${ }^{31,3}$ but Rosenbaum et al. ${ }^{32}$ claim that $\mathrm{NaF}$ generally does not affect acid phosphatase activity as shown by the azo dye method in rabbit liver sections, although it does inhibit staining with the Gomori method. Some of our gels were incubated in $0.01 \mathrm{M}$ potassium fluoride before staining with $\beta$-GP or $p$-NPP. There was a marked inhibition of all components, even though the zone on the cathodal side from mouse liver showed some activity after fluoride incubation.

Alloxan is said to inhibit one of the acid phosphatases in guinea-pig liver. ${ }^{9}$ When this compound is added to the staining mixture $(\alpha-N P)$ all bands changed to a red colour and there was almost no background stain in the gels. It seemed as if some bands on the positive side were most inhibited in rat and mouse liver and rat spleen. The coupling of $\alpha$-naphthol to the diazo compound is, however, reported to be affected by alloxan ${ }^{16}$ and when the running time was increased it was difficult to see any definite inhibition.

When preincubated in $0.02 \mathrm{M}$ sodium tartrate for $1 / 2 \mathrm{~h}$ before staining, most of the bands on the cathodal side disappeared from mouse liver and kidney and rat kidney. The anodal bands seemed to be much the same both with and without tartrate. Acid phosphatases from human prostate are said to be inhibited by tartrate ${ }^{25}$ but surprisingly we found only the band at the start to be inhibited and the other components to be, if anything, stronger.

Manganese-ions $(0.0005 \mathrm{M})$ seemed to have an overall inhibitory effect, but as mentioned above magnesium chloride increased activity and was absolutely necessary when using $\beta$-GP as substrate in combination with citrate in the electrophoresis buffer.

Malonate $(0.01 \mathrm{M})$ did not seem to have any activating effect when added to the staining mixture but was to some extent inhibitory, except for the fastest anodal components from mouse liver. When samples of mouse liver were incubated with and without malonate before electrophoresis there were activity differences, the fast-moving enzymes being activated by the malonate.

Developmental differences. For comparison with adult animals we also included foetal or newborn individuals from some species. Some tissues, e.g. kidney, did not seem to change their acid phosphatase pattern much during the ontogenetic development of mouse and rat (Fig. 9). The liver on the other hand showed definite changes. In the very young rats the cathodal components are stronger than in the adult animals but the opposite is true for the anodal ones. In foetal mice the anodal zone is much weaker than in adults. In the chicken there are changes in both kidney and liver as shown in Fig. 12. 
In rabbit liver it is reported ${ }^{32}$ that cytochemical staining for acid phosphatases with glycerophosphate as substrate and the azo dye method gives different results in adult and newborn animals. The lead precipitation method is said to give no staining in adult livers whereas in newborn livers it does. The naphthylphosphate gives staining in both newborn, juvenile, and adult individuals. A comparison of livers and kidneys from a newborn and an adult rabbit can be seen in Fig. 11. There are some differences to be noted, especially when $\beta$-GP is used as substrate with which the adult liver gave hardly any staining. There seems to be a quantitative shift in the relative strengths of two of the major components.

So far no clear qualitative genetic differences visible in the gels have been found, when leucocytes from five humans and livers from four different mouse and five rat strains were compared.

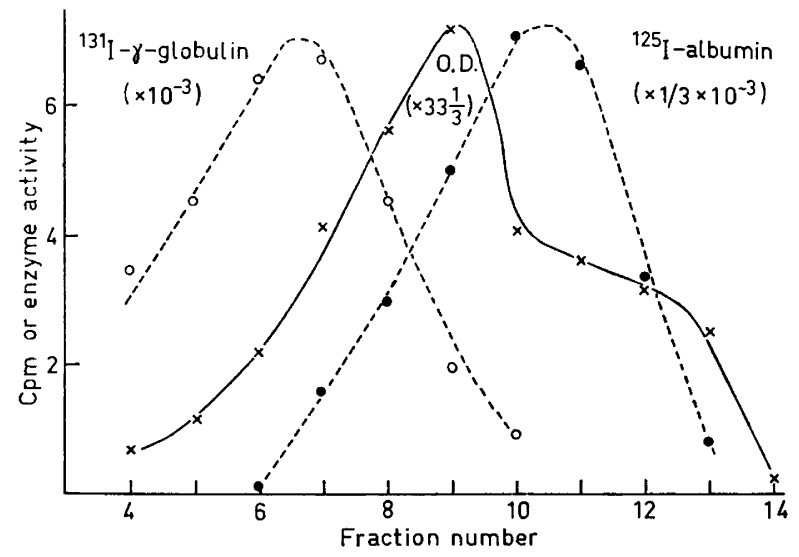

Fig. 15. Density gradient centrifugation, 10-30\% sucrose, supernatant from rat liver homogenate (16 h at $40000 \mathrm{rpm})$.

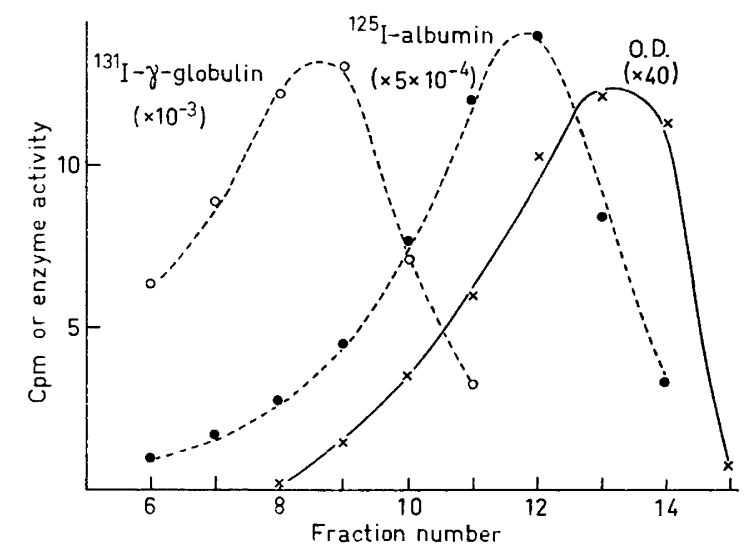

Fig. 16. Density gradient centrifugation, $10-30 \%$ sucrose, haemolysate from rat erythrocytes $(16 \mathrm{~h}$ at $40000 \mathrm{rpm})$.

Acta Chem. Scand. 20 (1966) No. 9 
Density gradient centrifugations. Results with rat liver can be seen in Fig. 15 . A bump is seen on the phosphatase curve. Our suggestion is that this is due to the acid phosphatase activity in the erythrocytes which are present in the liver. To test this we applied the same procedure to rat erythrocytes as can be seen in Fig. 16. This time we got a quite different curve with a maximum above the albumin in the tube. The erythrocyte maximum is at the same place as the bump on the other phosphatase curve. The calculated S-values for the acid phosphatases from rat liver, kidney, and erythrocytes are 5.4, 5.4, and 3.2 , respectively.

\section{DISCUSSION}

As might be expected, there are clear phylogenetic differences when the enzyme patterns from different species of animals are compared. Thus, the mouse, rat, and hamster have some acid phosphatase proteins with higher isoelectric points than any of the components from human, rabbit, and chicken. These proteins move to the cathode, even when the $\mathrm{pH}$ is around 6. Of the species investigated the rat and hamster seem to have the greatest range of net charges of their acid phosphatases as judged from the total length of their liver zymograms. At the other extreme comes the axolotl and the rabbit with different components located rather close to each other.

An alternative explanation for the multiple components than differences in electrical charge is that we are dealing with proteins which are polymers like those found in human haptoglobin types $2-1$ and $2-2$. The data from the density-gradient centrifugations suggest that the multiple bands of acid phosphatase activity are due to molecules which do not differ in size; hence this explanation is not likely to be correct. However, one likely explanation for the complex pattern found in several of the species under investigation seems to us to be that the proteins are polymers formed by combination of two or more different polypeptide chains. This situation is found in many proteins, including haemoglobins, gamma globulins and lactic dehydrogenases. ${ }^{33-37} \mathrm{~A}$ system with three different chains combining at random into tetramers should give fifteen different proteins. This figure is close to the number of bands seen in zymograms of human tissues. It seems reasonable to suppose that the zone containing many bands on the anodal side of the zymograms from livers, spleens, and some other tissues from humans, rats, mice, and rabbits, is composed of homologous enzymes in the different species. On the other hand it is more difficult to see which of the enzymes in humans and rabbits correspond to the five bands found in zymograms from rats and mice on the cathodal side of the starting point.

We have so far failed to obtain recombination of subunits in the enzymes in a mixture of tissue homogenate supernatants from two species. Dialysis at low and high pH's (3.3 and 10.0) failed to give any evidence of recombination as did freezing of the mixtures with $6 \mathrm{M} ~ \mathrm{NaCl}$. It may be necessary to break $\mathrm{S}-\mathrm{S}$ bridges before recombination takes plase. Domanski et al. ${ }^{38}$ reported that human prostatic acid phosphatase contains 10 disulfide groups per molecule. If genetic differences exist which would show as changed locations of one or several bands in the zymograms, they would be of great value for information of the structure of the enzyme systems. 
In comparison with most other attempts to resolve the acid phosphatase patterns of mammalian tissues by means of zone electrophoresis this investigation seems to give a more detailed structure and better resolution, excepting perhaps the report by Sur et al. ${ }^{25}$ Barka ${ }^{19,26}$ has described six zones of activity on polyacrylamide gels when he investigated rat liver, but he found only three components without chromatographic prefractionation and addition of Triton X100. In rat brain Anderson et al. ${ }^{18}$ found three acid phosphatase zones with the disc electrophoresis technique. One of these is thought to be associated with slowly moving high molecular weight proteins. The main reason for the resolution of the zones in many bands in our investigation is probably the rather low $\mathrm{pH}$ used during the electrophoretic procedure compared to the buffer systems used by other investigators, who have usually worked around $\mathrm{pH}$ 8.5. Sur et al. ${ }^{25}$ used a buffer system with $\mathrm{pH} 6.2$ and they got a similar pattern to ours from human prostate. The $\mathrm{pH}$ itself is, however, not enough to give good separations. A discontinuous buffer system definitely gives a better resolution than a continuous one.

There is of course always the possibility that the occurrence of these multiple bands is caused by some technical artefact. However, some facts suggest that we are dealing with a phenomenon of biological significance and that these different forms of acid phosphatases are likely to be present in vivo. First, it is possible to produce similar results with serveral different electrophoretic systems. Both starch gel and polyacrylamide gel as supporting media reveal multiple bands (Figs. 2 and 6). Even when the acetate buffer is used in combination with starch gel we could see multiple bands when human tissues and rabbit liver were run. Secondly, livers and spleens from several species of mammals show similar multiplicity, and many human tissues resemble each other in this respect. Thirdly, the patterns are reproducible even when the samples have been incubated at $37^{\circ} \mathrm{C}$ for more than $2 \mathrm{~h}$. The difficulty we have experienced in obtaining recombination or altered types of enzymes when samples from two species were mixed and dialysed together under acidic or alkaline conditions also points to considerable stability.

It has not been possible to demonstrate any acid phosphatases when human blood sera have been run. The reason is probably that the activity is too low even when the amount of acid phosphatases in blood is increased as in certain diseased states. A mouse serum gave some staining. Alkaline phosphatases from human sera are on the other hand rather easy to stain in almost all individuals.

Much work has been done on acid phosphatases with histochemical and biochemical methods including cell fractionation. Non-specific acid phosphatases have been shown to be located within the lysosomes, ${ }^{39,1,4,40,2}$ like many other acid hydrolases, with the aid of cell fractionation and histochemical techniques. One of the questions that has arisen is whether all the acid phosphatases are confined to the lysosomes. Some authors believe the acid phosphatases to be present in vivo both in particulate and non-particulate form. Neil and Horner ${ }^{11}$ have found evidence for four different acid phosphatases in mouse liver. One is microsomal and is probably identical with glucose-6phosphatase. Two seem to be located in heavier particles and one is claimed to be present in the non-particulate cytoplasm. By chromatography four iso-

Acta Chem. Scand. 20 (1966) No. 9 
enzymes, with acid phosphatase activity from human and rat liver homogenates, have been separated ${ }^{27}$ and their relative partition in the cell fractions determined. It appeared that one of the isoenzymes was predominantly in the lysosomal fraction and that two of the others had highest activity in the supernatant. There were, however, no absolute qualitative differences between the different cell fractions. How these different enzymes compare with our components is not yet clear. Since all cell fractionation methods certainly damage lysosomes in some degree it is difficult to conclude with confidence that a special acid phosphatase is free in the cytoplasm.

Another of the acid hydrolases, $\beta$-glucuronidase, is said to be located in both the lysosomes and the microsomes of mouse ${ }^{41}$ and rat liver. ${ }^{1}$ Our investigation showed that in human liver we have at least three and in the kidney at least two different proteins with $\beta$-glucuronidase activity. Furthermore in human leucocytes one enzyme with this activity is present which is different from the ones in liver and kidney. In ox spleen the possible existence of at least three $\beta$-glucuronidases has been reported..$^{30}$ It has also been shown ${ }^{42}$ that there are differences in the amount of free cytoplasmic activity between different tissues from mice. If in the human liver, there is a distribution of $\beta$-glucuronidase activity between lysosomes and microsomes, then there are the possibilities that the lysosomes contain one or two of the components and that the microsomal one is the third, but on the other hand all three components might be more or less equally distributed between the two fractions.

If we turn to the cytochemical methods in an attempt to answer this problem, and especially those investigations done with electron microscopy, we find that some investigations locate all or almost all acid phosphatase activity to discrete granules. ${ }^{5,15}$ In fact, acid phosphatase activity has been used to correlate the biochemical lysosome concept with possible particulate structures found with electron microscopy. On the other hand, Goldfischer et $a l .{ }^{12}$ have reported acid phosphatase activity also in the Golgi apparatus and in the endoplasmic reticulum. A diffuse general cytoplasmic staining located outside the lysosomes is sometimes found which could be due to an acid phosphatase. ${ }^{4,16}$ The demonstration of acid phosphatase activity in the Golgi apparatus seems to be confined to certain cell types, but may as Novikoff and co-workers ${ }^{40,43}$ have suggested, point to a relationship between these organelles and the lysosomes.

We have not yet made any attempts to correlate the electrophoretic patterns with different cell fractions. One component which is common to all tissues investigated from mice and rats and the only one present in demonstrable amounts in the brain is the one moving most rapidly towards the cathode. As lysosomes are shown to exist and to contain acid phosphatase in brain tissue ${ }^{\mathbf{3 9 , 4 4}}$ this component is probably of lysosomal origin in other tissues as well. Whether it is exclusively located there cannot be concluded from our results.

Fluoride has been shown to inhibit the particulate acid phosphatases in different cell types. We obtained an inhibition of all the components in some of the tissues when our gels were incubated with fluoride before staining. Hence it was not possible on this basis to identify some of the enzymes as being lysosomal. The component in mouse liver most likely to be lysosomal, for reasons 
just mentioned, still had some activity after fluoride incubation with $\beta$-GP as substrate. The corresponding zone from rat kidney though normally stronger was completely inhibited. It may be that the acid phosphatases from the rat are more susceptible to fluoride than those from the mouse.

It is a little surprising to see that human prostate has many components of acid phosphatases in common with several other tissues and that only one of its bands seems to be inhibited by tartrate, in view of the use of tartrate as a differential inhibitor for prostatic acid phosphatase. This component is, however, probably unique for the prostate. It seems then as if only part of the acid phosphatases of the prostate is inhibited and that the other enzymes with this activity are unaffected. Even the acid phosphatases on the cathodal side from rat and mouse liver are clearly inhibited by the tartrate to a much greater extent than those on the anodal side.

Incubation of homogenates of mouse liver with malonate is said to activate a large granule acid phosphatase. ${ }^{11}$ When we added malonate to the staining solution, it seemed to have a general inhibitory effect, except on the fastmoving part on the anodal side in mouse liver. This part is activated when the sample is preincubated with malonate before the electrophoresis.

$\alpha$-Naphthylphosphate and $\beta$-glycerophosphate are apparently hydrolyzed by the same enzymes as judged by the similar patterns they give after starchgel electrophoresis of samples from human prostate and rat kidney, even if some components differ in their relative activity against the two substrates. This indicates that one and the same lysosome probably shows a staining reaction with both the azo dye and the Gomori methods. However, some differences have been noted in cytochemical work with the two techniques ${ }^{\mathbf{4 5}, 32}$ when different species of animals were investigated. The two methods gave different results in rabbits and dogs ${ }^{45}$ but not in eight other species, including man. They seem to give similar results in newborn rabbits. ${ }^{32}$ The results seen in our gels confirm these differences for the rabbit. Liver from newborn rabbit has two acid phosphatases which give a clear reaction with $\beta$-GP (Fig. 11) whereas liver from adults does not give a reaction that is strong enough to be seen. Kidney from newborns gives a reaction with $\beta$-GP in the location of the slowest band seen with $\alpha$-NP. This enzyme is also present in spleen and liver from newborns and in liver from adults but its concentration seems to be much smaller than in kidney from newborns. This may explain why other tissues do not give a visible reaction with $\beta$-GP in this location. The azo dye method, which seems to be more sensitive, shows such enzymes in all these tissues. There are thus no absolute differences between livers from adults and newborns but a shift in relative and perhaps also absolute concentrations of the acid phosphatases.

Even though it is impossible to obtain discrete bands when the gels are incubated with $p$-nitrophenylphosphate because of the rapid diffusion of the product, one can obtain indications of where the strongest activities are located. This was done with the continuous acetate buffer for the electrophoresis because this system gives the strongest activity although the resolution is poor. The components giving the heaviest staining reaction with the other substrates seem to do the same with $p$-nitrophenylphosphate. Fluoride was inhibitory but there seemed to be some resistance on the cathodal side of the mouse liver.

Acta Chem. Scand. 20 (1966) No. 9 
Acknowledgements. We are grateful to Professor J. A. Böök whose help and support allowed one of us (L.-G. L.) to work at the National Institute for Medical Research. We are also grateful to Dr. T. Freeman and Dr. J. Tata for supply of material.

This work has been supported by a grant to Professor J. A. Böök from the U.S. National Institutes of Health (Research Grant No. B-4320).

\section{REFERENCES}

1. De Duve, C., Pressman, B. C., Gianetto, R., Wattiaux, R. and Appelmans, F. Biochem. J. 60 (1955) 604.

2. Straus, W. J. Biophys. Biochem. Cytol. 2 (1956) 513.

3. Sobel, H. J. J. Endocrinol. 30 (1964) 323.

4. Ericsson, J. L. E. and Trump, B. F. Lab. Invest. 13 (1964) 1427.

5. Trump, B. F. and Ericsson, J. L. E. Exptl. Cell Res. 33 (1964) 598.

6. Goodlad, G. A. J. and Mills, G. T. Biochem. J. 66 (1957) 346.

7. Macdonald, K. Biochim. Biophys. Acta 58 (1962) 356.

8. Neil, M. W. Biochem. J. 81 (1961) 41 P.

9. Neil, M. W. and Horner, M. W. Biochem. J. 84 (1962) 32P.

10. Neil, M. W. and Horner, M. W. Biochem. J. 92 (1964) 217.

11. Neil, M. W. and Horner, M. W. Biochem. J. 93 (1964) 220.

12. Goldfischer, S., Essner, E. and Novikoff, A. B. J. Histochem. Cytochem. 12 (1964) 72.

13. Sobel, H. J. Endocrinology 68 (1961) 801.

14. Tice, L. W. and Barrnett, R. J. Anat. Record 147 (1963) 43.

15. Warner, S. P. J. Roy. Microscop. Soc. 83 (1964) 397.

16. Večerek, L. Z. B. and Pelichova, H. Histochemie 3 (1964) 428.

17. Allen, S. L., Misch, M. S. and Morrison, B. M. J. Histochem. Cytochem. 11 (1963) 706.

18. Anderson, P. J., Song, S. K. and Christoff, N. Proc. 4th Intern. Congr. Neuropathol. 1 (1962) 75.

19. Barka, T. J. Histochem. Cytochem. 9 (1961) 542.

20. Barron, K. D., Bernsohn, J. and Hess, A. R. J. Histochem. Cytochem. 12 (1964) 42.

21. Castor, C. W. and Prince, R. K. Lab. Invest. 12 (1963) 38.

22. Hopkinson, D. A., Spencer, N. and Harris, H. Nature 199 (1963) 969.

23. Shibko, S. and Tappel, A. L. Biochem. Biophys. Acta 73 (1963) 76.

24. Sur, B. K., Moss, D. W. and King, E. J. Biochem. J. 84 (1962) 55P.

25. Sur, B. K., Moss, D. W. and King, E. J. Proc. Assoc. Clin. Biochem. 3 (1962) 11.

26. Barka, T. J. Histochem. Cytochem. 9 (1961) 564.

27. Reith, A. E. and Schmidt, F. W. Klin. Wochschr. 42 (1964) 915.

28. Charlwood, P. A. Anal. Biochem. 5 (1963) 226.

29. Golberg, L., Martin, L. E. and Leigh, J. Biochem. J. 85 (1962) 56.

30. Mills, G. T., Paul, J. and Smith, E. E. B. Biochem. J. 53 (1953) 232.

31. Macdonald, K. Biochem. J. 80 (1961) 154.

32. Rosenbaum, R. M. and Rolon, C. I. Histochemie 3 (1962) 1.

33. Boyer, S. H., Fainer, D. C. and Watson-Williams, E. J. Science 141 (1963) 642.

34. Edelman, G. M. and Poulik, M. D. J. Exptl. Med. 113 (1961) 861.

35. Rhinesmith, H. S., Schroeder, W. A. and Martin, N. J. Am. Chem. Soc. 80 (1958) 3358.

36. Shaw, C. R. and Barto, E. Proc. Natl. Acad. Sci. U.S. 50 (1963) 211.

37. Zinkham, W. H., Blanco, A. and Kupchyk, L. Science 144 (1964) 1353.

38. Domanski, J., Konieczny, L. and Ostrowski, W. Biochim. Biophys. Acta 92 (1964) 405.

39. Beaufay, H., Berleur, A. M. and Doyen, A. Biochem. J. 66 (1957) 32P.

40. Novikoff, A. B., Essner, E. and Quintana, N. Federation Proc. 23 (1964) 1010.

41. Paigen, K. Exptl. Cell Res. 25 (1961) 286.

42. Conchie, J., Hay, A. J. and Levvy, G. A. Biochem. J. 79 (1961) 324.

43. Novikoff, A. B., Quintana, N., Villaverde, H. and Forschirm, R. J. Cell Biol. 23 (1964) $68 \mathrm{~A}$.

44. Tewari, H. B. and Bourne, G. H. J. Anat. 97 (1963) 65.

45. Ragins, H., Dittbrenner, M. and Diaz, J. Anat. Record 150 (1964) 179.

Received June 14, 1966.

Acta Chem. Scand. 20 (1966) No. 9 